\title{
THE CHANGING ROLE OF THE TEXTILE ENGINEER
}

$I^{\mathrm{N}}$

$\mathrm{N}$ his inaugural lecture as research professor of toxtile engineering in the University of Leeds, now published by the Leeds University Press *, Prof. P. Grosberg pointed out that the textile engineer still plays a very large part in the day-to-day work of the designer of textile machinery. However, partly owing to tho general shortage of trained engineers, engineering designers of good quality are scarce in this branch of industry, and until very recently most basic changes and design coneepts with regard to textile machinery resulted from the creative ideas of the textile manufacturers. Fundamentally, the lack of precision in our knowledge of textile processing derived from the difference in kind between tho manipulations performed by textile machinery and those performed by all other manipulative machinery. The basic purpose of textile processing was to take fibres arranged in one pattern and rearrange them in a second pattorn. As this was done indirectly, textile processes tended to be of a statistical nature and there might be 40-100 manipulative processes of one kind or another in the chain between clean wool and cloth. Moreover, since the magnitude of changes produced by processing was never measured nor was there any clear idea of how these changes were produced, it was not surprising that no major change in the design of textile machinery occurred from the time such designs reached a developed mechanical form in the nineteenth century until 1946.

The present change in the role of the textile engineor started after the Second World War with the changes in the position of textilo machinery manufacturers which resulted from the increased international form of the market, the consequent necessity to improve the machines and to consider them as part of the chain of oporations the efficiency of which must be maximized, and thirdly, with the change in the structure of the industry resulting from the production of man-made fibres. This was especially so in the last-mentionod case in their use in blends with natural fibres, and the consequent need for theoretical and technological understanding of the problems involved. The trend to large vertical organizations with their economic advantages also stimulated the search for an exact knowledge of the factors involved in textile processing. The research chair of wool textile engineering at Leeds was founded in 1947, mainly to act as a nucleus around which changing points of view on the purpose and

* The Changing Role of the Textile Engineer. By Prof. P. Grosberg. (An Inaugural Iecture delivered in the University of Leeds on 14 January, 1963.) Pp. 14. (Leeds: The University Press, 1963.) 2s. 6d. aims of textile manipulations could be crystallized; however, the more conventional engineering problems of textile machinery have not been neglected. Without doubt, the main interest in textile engineering research lies in the understanding of the goomotrical changes that occur in processing and their effect on the properties of the resulting textile material. The object of textile processing, according to Prof. Grosberg, could be considered to be a method of arranging fibres so that both the maximum strength and the ease of blending of the arrangement should be the sum of the strengths and blending resistances of the constituent fibres. This was vory nearly achieved by traditional textile processing, but it was only in tho past decade that the careful examination of the fibres in a twisted yarn had led to a more realistic model in which the helices become spirals of varying radius.

Tho knowledge that a limit of regularity exists had been an important advance, but investigations into why some yarns are much more irregular than this limiting or ideal yarn had run into many difficulties. All those investigations too had demonstrated the necessity for the fibres to be reasonably parallel and disentangled for rollor drafting to operato successfully. An early need of the textile engineer who wished to modify existing processes was to disentangle the true from the supposed purpose of many textile machines. The manufacture of yarn was only part of the processing sequence and there was a lack of knowledge of the effect of geometrical changes in the cloth in its mechanical proportions. Howover, investigations have already made it clear that some of the finishing processes are indirect methods of obtaining geometrical changes within the material which cannot be detected merely by measuring the area changes occurring in the cloth. The vital changes of the past decado in spinning and knitting have shown the very closo connexion existing between a proper knowledge of the ond-product and a correct design of the machine to produce it. It was to bo hoped that the finishing trade might soon benefit from a more rational approach and so place the design of plant for this section of the industry on a more rational basis. Finally, as a result of this new necessity for the textile engineer to understand the requirements of the process for which he designed and made machinery, Prof. Grosberg pointed out, a new emphasis in his training was needed, and that training in future should provide a fundamental knowledge of fibre science, eloth and yarn properties, and what could only be called 'toxtile enginooring' itself.

\section{GALATHEA DEEP-SEA ISOPODS}

T HE Galathea Reports, in which the scientific results of the 1950-52 Danish Deep-Sea Expodition are published, need no introduction to marine biologists. In 1956, Torben Wolff, deputy leador of the expedition, described the isopod crustaceans obtained from depths exceeding $6,000 \mathrm{~m}$ from the Banda, Kermadec and Philippine Trenches. Of the twelve hadal (ultra-abyssal) species, eight were new and seven of them belonged to known genera of the Asellota.

The same author has now prepared an account of the systematics and biology of the bathyal and abyssal species of Asellota from depths between 200 and $6.000 \mathrm{~m} *$. The total of 83 specimens is not impressive when compared with those of some other deep-sea expeditions, but they are referable to 23 species of which all but two are new and three belong to new genera. In addition, thousands of specimens collected by the Challenger, Albatross, Thor, Ingolf and other expeditions have boon re-examined and some families, genera and species have been revised. Keys to the determination of all the gonera of all families, and of the species of those genera that are treated in detail, have been prepared. As a result of this revision, the author has described seven additional new species, established three new genera for previously known species, and 'invalidated' a number of recently established families

* Galathea Report, Vol. 6: The Systematics find Biolopy of Bathyal and Abyssal Isopcda Asellota. (Scientifle Results of the Danish Decp-Sea Expedition Round the World $1950-52$.) By Dr. Torben Wolff. Pp. $200+19$ plates.
(Copenhagen : Danish Science PresB, Ltd., 1962.) 120 Danish kr. 
while accepting others. The systematic part is preceded by a short historical review of the literature on deepwater asellotes from 1869 to 1962 , also sections on morphological and oceanographical terms and on the significance of various morphological characters in taxonomy.

Very little is known of the feeding habits, reproduction and development in abyssal isopods. It has been assumed that where temperature and other physical factors are so constant, breeding would occur throughout the year. The post-marsupial development of some deep-water species of Haploniscus is described and compared with that of the littoral Jaera albifrons. The results of a careful examination of more than 1,400 adult specimens of bathyal and abyssal Paraselloidea pertaining to 11 families are tabulated and analysed. Females predominated in all but one family. 75 per cent of the females were without a marsupium, those with no trace of developing oostegites being rather fewer than those with developing oostegites. In three families none of the females had developing oostegites, whereas in another family none lacked them. This may indicate that in all four families there is only one preparatory stage before sexual maturity instead of the more usual two stages. Only a third of the females with marsupium carried ova or embryos (8 per cent of all females examined). This paucity of ovigerous females may indicate that breeding is seasonal in many species of these Asellota and that many were not breeding during the summer months when most of the collecting was done. A few anomalous 'intermediate' specimens are described.

The effect of increasing depth on body size and relative length of limbs is discussed. Pigmented eyes have been observed in two abyssal species of Stenetrium. The intestinal contents of specimens pertaining to 14 species were examined. In the two pelagic species coccoliths and fragments of amphipods predominated, but one specimen had also spicules of various sponges, proving that it can feed on the bottom. Detritus, mineral fragments and dead tests of various protozoons were abundant in the majority of the benthic species, but fragments of hydroids, polychæte worms, isopods and amphipods were fairly common. A species of Bathyopsurus had, in addition to a few sponge spicules and amphipod remains, large quantities of masticated Sargassum or allied algal genus. The seaweed had apparently been eaten in the fresh condition, soon after it had sunk to the ocean bed, and on it were several identifiable hydroids. The substrata vary greatly from sand to very stiff clay, globigerina or pteropod ooze; several species were collected from different types of sediments.

The section on the distribution of marine Asellota (excluding the freshwater Aselloidea), and the extensive bibliography, should prove invaluable to all students of the group. The named species total 633, including many new ones described in recent American and Russian publications. Twenty species of Janiridae are predominantly freshwater; of the 613 marine species only six are pelagic. The species are listed strictly according to depth limits, but regional distribution, temperature, and number of records are also given. Since temperatures are seldom included in systematic papers, the author has had to glean these from various sources. When temperature is considered together with depth a number of species should be transferred to other zones (listed on p. 271). This may be done with some confidence in the case of species known from several localities. The bathymetrical distribution of species, genera and families is analysed in detail. A list of species which are truly representative of the zones ranging from 200 to $11,000 \mathrm{~m}$ is given; 38 species have vertical ranges exceeding $2,000 \mathrm{~m}$ and two of these have ranges exceeding $5,000 \mathrm{~m}$. The geographical distribution is analysed in much the same way for species, genera and families. Although our knowledge of abyssal Asellota is still very incomplete, it is evident that many of the species have a very restricted geographical range. This high rate of endemism, characteristic of other Peracaridan orders (Cumacea, Amphipoda), is in marked contrast to the more cosmopolitan distribution of species of the abyssal family of sea-stars, the Porcellanasteridae. In the Peracarida the young are incubated in a marsupium and, when liberated, their dispersal would be very restricted.

This is the nearest approach to a monograph of the Asellota so far attempted. It is well planned and on the whole well written; only occasionally in discussion parts does the author fail to make his meaning quite clear. He sometimes makes rather sweeping statements, such as that on neoteny in Crustacea (p. 21). He is not alone in adhering to the use of 'tribe' instead of 'superfamily' (it never was equivalent to sub-order as on p. 17) although, according to the International Code of Zoological Nomenclature (p. 163; 1961), tribe is subordinate to the sub-family. But these are minor flaws in a major work, and Dr. Wolff is to be congratulated on the results of years of dedicated study.
ISABELLA GORDON

\title{
A CENTRIFUGE FOR SEPARATION AND COLLECTION OF FRACTIONS IN SEPARATE CONTAINERS UNDER STERILE CONDITIONS
}

\author{
By Dr. P. UNGER, Dr. O. RAMGREN, P. POLLAK and H. BROSTRÖM \\ City of Stockholm Blood Transfusion Centre, Stockholm 38
}

\begin{abstract}
$\mathrm{T}$ HE centrifuge to be described has been devised for the purpose of separating phases of different density present in a suspension.

The primary feature of the system is the utilization of the centrifugal force to channel the fractions into separate containers, thereby overcoming the main obstacle encountered using present-day available techniques, that is, the difficulty of isolating the various fractions at removal of the centrifugal field. Although the problem is readily overcome by the use of continuously working industrial separators, their application is, in many instances, incompatible with medical laboratory practices-inasmuch as they scarcely meet prerequisites regarding sterile operation. Furthermore, and this is important, they produce only two, or at best three, separate fractions.
\end{abstract}

As regards other approaches to the problem of separating particles by centrifugation than use of conventional centrifuges, the following main principles have to be recognized: Ultracentrifugation ${ }^{1}$ (for analytical purposes), density gradient centrifugation ${ }^{2}$ (analytical-preparative), and counter current centrifugation ${ }^{3}$. These all represent the 'single container' type. Regarding principles utilizing more than one 'container', the Cohn $A D L$-centrifuge ${ }^{4}$ and the threshold centrifuge ${ }^{5}$ should be mentioned. All these have been of great value to us in our search for a centrifugal system to complement our present research facilities.

The guiding principle of our work over the past years has been the development of a system, enabling simultaneous large-scale separation and collection of fractions 